\title{
Responses of photosynthetic characteristics and enzyme activity of nitrogen metabolism to low nitrogen in maize with different nitrogen tolerance
}

\author{
Pengtao $\mathrm{Ji}^{1}$, Yongwei Cui ${ }^{2}$, Xiangling $\mathrm{Li}^{3}$, Kai Xiao ${ }^{1}$, Peijun Tao ${ }^{1 *}$, Yuechen Zhang ${ }^{1}$ \\ (1. College of Agronomy, Hebei Agricultural University/State Key Laboratory of North China Crop Improvement and Regulation, \\ Baoding 071001, Hebei, China; \\ 2. Academy of Agricultural Planning and Engineering, Ministry of Agriculture and Rural Affairs, Beijing 100125, China; \\ 3. College of Agronomy and Biotechnology, Hebei Normal University of Science \& Technology, Qinhuangdao 066004, Hebei, China)
}

\begin{abstract}
Understanding the physiological processes associated with leaf photosynthetic characteristics and nitrogen (N) assimilation during grain-filling stage are helpful for enhancing nitrogen utilization efficiency (NUtE) of maize. In this study, the leaf photosynthetic and $\mathrm{N}$ assimilation parameters in maize, including Zhengdan 958 (ZD958), a low-N tolerance cultivar and Huanong 138 (HN138), a low-N sensitive cultivar under different N rates were examined. Results showed that ZD958 displayed significant increases on grain yield and NUtE than that in HN138. Analyses on the leaf photosynthetic and N assimilation-associated processes indicated that ZD958 had higher leaf $\mathrm{N}$ remobilization (Rem N), net photosynthetic rate (Pn) and photosynthetic $\mathrm{N}$ use efficiency (PNUE) with respect to those of HN138 during grain-filling stage. In addition, ZD958 was also shown to be higher activities of leaf nitrate reductase (NR), glutamine synthetase (GS), nitrate reductase (GDH) and glutamine synthetase (GAGOT) than those of HN138. The leaf PNUE was significantly positively correlated with NR, GS, GDH, GOGAT suggesting that leaf PNUE and NR, GS, GDH, GOGAT jointly determined the N remobilization efficiency and the leaf $\mathrm{N}$ remobilization during post-silking. These results suggested that ZD958 possessed improved PNUE, NR and GS activities in leaves during grain-filling stage that contributes improve grain weights and yield formation capacities upon under low-N conditions.
\end{abstract}

Keywords: low-N, photosynthesis, nitrogen assimilation, nitrogen utilization efficiency, maize DOI: $10.25165 /$ j.ijabe.20201306.5891

Citation: Ji P T, Cui Y W, Li X L, Xiao K, Tao P J, Zhang Y C. Responses of photosynthetic characteristics and enzyme activity of nitrogen metabolism to low nitrogen in maize with different nitrogen tolerance. Int J Agric \& Biol Eng, 2020; 13(6): 133-143.

\section{Introduction}

Nitrogen $(\mathrm{N})$ is the critical limiting nutrient for most crops. Globally, over 110 million tons of $\mathrm{N}$ fertilizer is applied annually to maximize crop yields. Application of $\mathrm{N}$ fertilizers contributes greatly to the increase of the grain protein content, biomass and economic yield of maize. However, excessive nitrogen applications can reduce nitrogen use efficiency (NUE), which pose a potential threat to the ecological environment ${ }^{[1,2]}$. Increasing maize $\mathrm{N}$ use efficiency (NUE) is an important approach to reduce fertilizer application and improve resource utilization efficiency. NUE is contributed by $\mathrm{N}$ utilization efficiency and $\mathrm{N}$ uptake

\section{Received date: 2020-05-08 Accepted date: 2020-10-15}

Biographies: Pengtao Ji, PhD, Research Associate, research interests: crop production system regulation engineering, Email: Jipengtao1987@126.com; Yongwei Cui, $\mathrm{PhD}$, Associate Professor, research interests: rural revitalization and modern agriculture, Email: cuiyongwei@126.com; Xiangling Li, PhD, Lecturer, research interests: crop production system regulation engineering, Email: ncqyfz2008@126.com; Kai Xiao, PhD, Professor, research interests: Crop cultivation physiology and crop anti-reverse molecular mechanism. Email: xiaokai@hebau.edu.cn; Yuechen Zhang, PhD, Professor, research interests: crop production system regulation engineering, Email: Zhangyc1964@126.com. *Corresponding author: Peijun Tao, $\mathrm{PhD}$, Professor, research interests: crop cultivation and agricultural extension. College of Agronomy, Hebei Agricultural University/State Key Laboratory of North China Crop Improvement and Regulation, Baoding 071001, Hebei, China. Tel: +86-13833046100, Email: taopeijun@sina.com. efficiency $^{[3]}$. Differences in $\mathrm{N}$ uptake and utilization vary significantly among genotypes ${ }^{[4,5]}$, The selection of $\mathrm{N}$-efficient cultivar varieties (cultivars with higher grain yield under low $\mathrm{N}$ condition) plays a significant role in improving the $\mathrm{NUE}^{[6,7]}$. Therefore, improvement on plant NUE through breeding high NUE cultivars together with suitable $\mathrm{N}$ fertilizer management can help accomplish the goal for optimized high yield.

In the maize reproductive stage, a portion of $\mathrm{N}$ storage in vegetative organs is remobilized to grain, of which, that stored in leaves contributes largely to the grain $\mathrm{N}$ accumulation ${ }^{[8]}$. The $\mathrm{N}$ of leaves is also required for photosynthesis to produce dry matter, hence, grain yield ${ }^{[9]}$. Additionally, excessive leaf $\mathrm{N}$ remobilization can lead to early senescence of leaf tissue. Therefore, it is a great challenge to increase $\mathrm{N}$ remobilization from leaves while ensuring high photosynthesis during the grain filling stage in maize. Photosynthetic $\mathrm{N}$ use efficiency (PNUE) represents the photosynthetic capacity of $\mathrm{N}$ content per unit leaf area, which is an important index indicating whether the photosynthetic capacity of the leaves and $\mathrm{N}$ use efficiency are coordinated $^{[8]}$. Numerous studies have reported that the modern maize cultivars have higher green leaf area duration, leaf $\mathrm{N}$ content, and post-silking $\mathrm{N}$ uptake ${ }^{[10-12]}$. Moreover, the maize cultivars to be low-N tolerant display higher net photosynthetic rate (Pn) and PNUE than those to be low-N sensitive under $\mathrm{N}$ deprivation conditions $^{[8,13-15]}$. The N-efficient cultivar (ZD958) had higher Pn and PNUE than N-inefficient cultivar (QS101) at low N application 
rates $^{[16]}$. Simultaneously achieve high yield and $\mathrm{N}$ remobilization efficiency, a maize cultivar might maintain the PNUE of lower leaves while increasing the PNUE of upper and middle leaves at the canopy-level ${ }^{[8]}$.

In plants, several physiological studies and recent genomic approaches have identified genes encoding enzymes involved in $\mathrm{N}$ metabolism that are specifically activated during $\mathrm{N}$ remobilisation ${ }^{[17,18]}$. Gutamine synthetase (GS) appeared to be one of the most characteristic biochemical events occurring during the transition from $\mathrm{N}$ assimilation to $\mathrm{N}$ remobilization ${ }^{[19-21]}$. The GDH is an enzyme capable of catalysing glutamate de-amination as well as glutamate synthesis, carries out the de-amination reaction in source leaves ${ }^{[22]}$. It has also been shown that GOGAT is still functional in senescing leaves and can participate in glutamate synthesis. These enzymes represent putative key reactions that may influence grain yield and its components ${ }^{[23]}$. In some crops, the N-efficiency or low-N tolerant genotype sustained relative higher NR and GS enzyme activities than those of the $\mathrm{N}$-inefficiency or low-N sensitive genotype, such as in maize $\mathrm{e}^{[24,25]}$, wheat ${ }^{[26]}$ and barley ${ }^{[27]}$.

Currently, although the process related to $\mathrm{N}$ uptake and remobilization were performed in maize, the physiological mechanisms associated photosynthetic parameters and $\mathrm{N}$ metabolism characteristic in ear-leaf of different low-N tolerances cultivars in response to $\mathrm{N}$ application are still largely characterized. The low-N tolerant maize cultivar possess higher photosynthetic function and much more improved $\mathrm{N}$ assimilation characteristic during post-silking stage were hypothesized. A

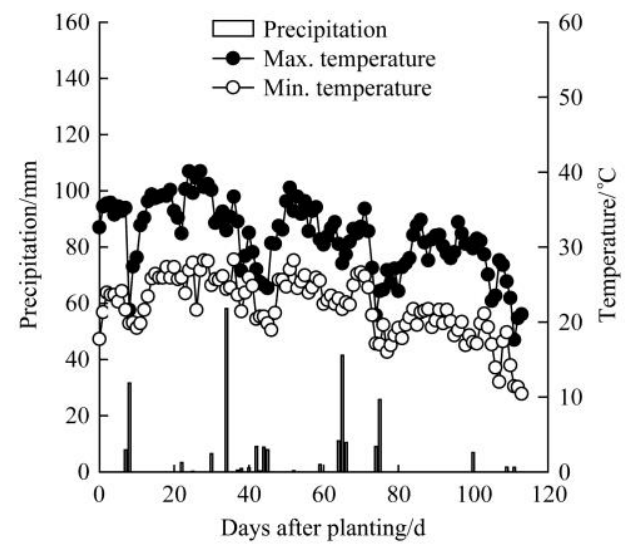

a. 2017 2-year field study using two maize cultivars with drastically different low-N tolerant were performed. The objectives of the study were to: (i) determine the physiological processes difference related to photosynthesis parameters and $\mathrm{N}$ metabolism in ear-leaf between low- $\mathrm{N}$ tolerant and low- $\mathrm{N}$ sensitive cultivars in maize. (ii) Analyze the correlations between these markers were then evaluated to determine whether or not they are linked to each other regardless of the genetic background, $\mathrm{N}$ application conditions, developmental stage. This study provides insights into the $\mathrm{N}$-associated physiological processes that maize species responds to $\mathrm{N}$ deprivation and puts forward guidance for breeding low-N tolerant and high NUtE maize cultivars under low-N conditions.

\section{Materials and methods}

\subsection{Site description}

The field experiments were conducted during the 2017 and 2018 growth seasons at Experimental Station of Hebei Agricultural University $\left(43^{\circ} 31^{\prime} \mathrm{N}, 124^{\circ} 48^{\prime} \mathrm{E}\right)$, Xinji city, China. The annual means on air temperature and precipitation from 1980 to 2010 were $13.8^{\circ} \mathrm{C}$ and $516.4 \mathrm{~mm}$ at the station, respectively. The daily air temperature and precipitation of 2017 and 2018 maize growth seasons were showed in Figure 1. The soil ( depth $20 \mathrm{~cm}$ ) texture for experiment was clay loam (ISSS classification, International Soil Science Society), with bulk density of $1.47 \mathrm{~g} / \mathrm{cm}^{3}$, and organic matter $18.47 \mathrm{~g} / \mathrm{kg}$, total nitrogen $1.25 \mathrm{~g} / \mathrm{kg}$, alkali-hydrolyzable $\mathrm{N}$ $91.55 \mathrm{~g} / \mathrm{kg}$, extractable Olsen-P $27.50 \mathrm{mg} / \mathrm{kg}$, and ammonium acetate extractable K $145.79 \mathrm{mg} / \mathrm{kg}$, pH 7.8 .

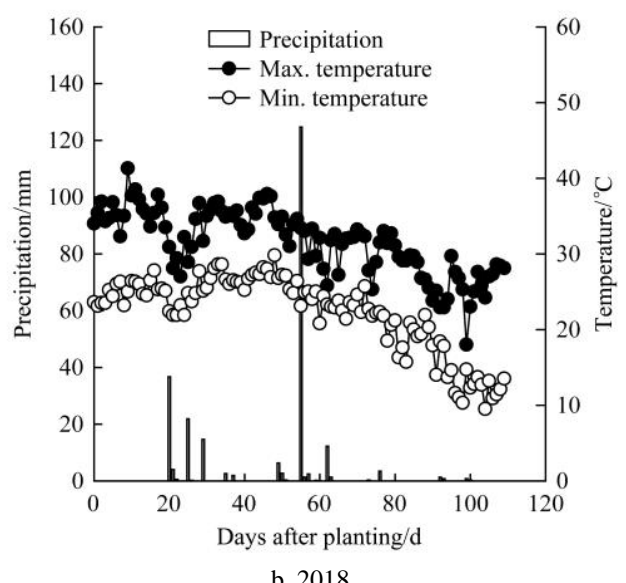

b. 2018

Figure 1 Daily precipitation and temperature during the 2017 and 2018 growing season of summer maize

\subsection{Experimental design}

Two maize cultivars, including Zhengdan 958 (ZD958) was to be low-N tolerant cultivar ${ }^{[28,29]}$ and Huanong 138 (HN138) was to be low-N sensitive cultivar ${ }^{[28]}$, were used in this study. Three $\mathrm{N}$ application rates, including 0,120 and $240 \mathrm{~kg} \mathrm{~N} / \mathrm{hm}^{2}$ (referred to as N0, N120 and N240, respectively), were established using urea as the $\mathrm{N}$ source. Of which, half was applied as basal and the other half was to topdressing at V9 stage (i.e. the $9^{\text {th }}$ leaf in plants was fully expanded). The cultivar and $\mathrm{N}$ rate were established based on a split plot design with three replicates, using nitrogen rate as main plots and cultivar as sub-plots. Seeds of maize were sown on June $14^{\text {th }}, 2017$, and on June $18^{\text {th }}, 2018$, respectively. The maize seedlings were thinned at the V5 stage to achieve a standard density of 67500 plants $/ \mathrm{hm}^{2}$. Each cultivar was planted in a distinct plot (20 m in length, with 8 rows). Basal phosphorus $\left(90 \mathrm{~kg} / \mathrm{hm}^{2} \mathrm{P}_{2} \mathrm{O}_{5}\right)$ and potassium $\left(120 \mathrm{~kg} / \mathrm{hm}^{2} \mathrm{~K}_{2} \mathrm{O}\right)$ were used for all of the plots. Other cultivation practices, such as irrigation (prior to sowing and at the heading stage), removal of weeds, and chemical control of diseases and pests, were performed in accordance with the recommended conventional approaches in North China Plain. The harvest dates during two growth seasons were October $5^{\text {th }}, 2017$, and October $7^{\text {th }}, 2018$.

\subsection{Assessment of dry matter amounts, yield components and} grain yield

The above-ground tissues of plants were harvested from silking to maturity with interval of 10 day each. Five plants of medium three rows per plot were sampled, then separated into various tissues, including leaves, stalks, cobs, husks, and grains (leaves and stalks at silking). All tissue samples were oven dried at $105^{\circ} \mathrm{C}$ for $30 \mathrm{~min}$ and dried to constant weight at $70^{\circ} \mathrm{C}$. Dry mass of the tissues was ground into powder after obtaining weight to assess contents of nutrients. Briefly, appropriate amount $(0.3 \mathrm{~g})$ of the ground materials were used to determine total nitrogen content by a modified Kjeldahl digestion method ${ }^{[30]}$. At maturity, 
the cobs from three center rows of each plot were collected to determine grain yield (moisture content $14 \%)^{[31]}$. One hundred-grain weights were determined, and the grain numbers per ear were recorded. $\mathrm{N}$ uptake of plants was calculated based on $\mathrm{N}$ concentration and the total above-ground biomass.

\subsection{Assessment of photosynthetic parameters in leaf}

Leaf area and Pn were measured every $10 \mathrm{~d}$ from silking to physiological maturity. Five plants with the same silking date were tagged in each plot. The five plants used for determination of Leaf area by the formula ${ }^{[32]}$. Leaf area $\left(\mathrm{cm}^{2}\right)$ was calculated as by leaf length $(\mathrm{cm}) \times$ maximum leaf width $(\mathrm{cm}) \times 0.75$. Leaf area index was calculated as by plant leaf area / land area. The ear-leaf of five plants per plot was measured Pn on clear sunny day between 09:00a.m. and 11:00a.m, using a portable photosynthetic system (CIRAS-3 USA) with a controlled light intensity of $1600 \mu \mathrm{mol} / \mathrm{m}^{2} \cdot \mathrm{s}$. The $\mathrm{CO}_{2}$ concentration in leaf chamber was controlled at $400 \mu \mathrm{mol}$ $\mathrm{CO}_{2} / \mathrm{mol}$ air. Using the leaf area, leaf dry weight, and leaf $\mathrm{N}$ content, the specific leaf $\mathrm{N}\left(\mathrm{SLN}, \mathrm{g} \mathrm{N} / \mathrm{m}^{2}\right.$ ) was calculated as $\mathrm{N}$ content $(\mathrm{g})$ per leaf area $\left(\mathrm{m}^{2}\right)$. PNUE $\left(\mu \mathrm{mol} \mathrm{CO}_{2} / \mathrm{g} \mathrm{N} \cdot \mathrm{s}\right)$ was calculated as $P_{n}$ per SLN (Sinclair et al. 1989). Leaf N content was calculated as leaf dry weight by $\mathrm{N}$ concentration.

\subsection{Assessment of $\mathrm{N}$ assimilation enzymatic activities in leaf}

The ear-leaf from five plants was sampled between 09:00 a.m. and 11:00 a.m. from silking to physiological maturity with interval of $10 \mathrm{~d}$ each. The fresh samples were immediately frozen in liquid nitrogen and stored at $-80^{\circ} \mathrm{C}$ for measurement the enzymatic activities of nitrate reductase (NR), glutamine synthetase (GS), nitrate reductase (GDH) and glutamine synthetase (GAGOT).

The activity of NR was measured using the method ${ }^{[33]}$. Fresh leaf samples $(0.5 \mathrm{~g})$ were placed in $10 \mathrm{~mL}$ of an incubation medium, which was $0.1 \mathrm{M}$ potassium phosphate buffer ( $\mathrm{pH} 7.5$ ) containing $0.1 \mathrm{M} \mathrm{KNO}_{3}$ with $1 \%(\mathrm{v} / \mathrm{v})$ propanol. Prior to the assay, the buffer solution was purged with $\mathrm{N}_{2}$ gas for $30 \mathrm{~min}$ to remove any dissolved oxygen. The samples were then vacuum infiltrated (two times) and subsequently incubated in a water bath at $30^{\circ} \mathrm{C}$ for $30 \mathrm{~min}$ in the dark. $1 \mathrm{~mL}$ samples were withdrawn, and the color reaction was initiated by adding $2 \mathrm{~mL}$ of aminobenzenesulfonic acid and $2 \mathrm{~mL}$ of a-naphthylamine. After $20 \mathrm{~min}$ of incubation, the amount of nitrite $\left(\mathrm{NO}_{2}^{-}\right)$was determined by absorbance at $520 \mathrm{~nm}$ using a standard curve by a spectrophotometer.

To assay the activity of GS, fresh leaf samples $(0.5 \mathrm{~g})$ of leaf tissue were homogenized with $3 \mathrm{~mL}$ of $10 \mathrm{mM}$ Tris- $\mathrm{HCl}$ buffer $(\mathrm{pH}$ 7.6, containing $1 \mathrm{mM} \mathrm{MgCl}, 1 \mathrm{mM}$ EDTA and $1 \mathrm{mM}$ 2-mercaptoethanol) via a chilled mortar and pestle. The homogenate was centrifuged at $15000 \times \mathrm{g}$ for $30 \mathrm{~min}$ at $4^{\circ} \mathrm{C}$. The supernatant was subsequently used to determine enzymatic activity. The glutamine synthetase activity was assayed according to the methods ${ }^{[30]}$. The reaction mixture contained $80 \mathrm{mM}$ Tris- $\mathrm{HCl}$ buffer, $40 \mathrm{mM} \mathrm{L}$-glutamic acid, $8 \mathrm{mM} \mathrm{ATP,} 24 \mathrm{mM} \mathrm{MgSO}$, and $16 \mu \mathrm{M} \mathrm{NH}_{2} \mathrm{OH}$ in a final volume of $1 \mathrm{~mL}$. The final $\mathrm{pH}$ was 8.0. The reaction was initiated by the addition of $0.1 \mathrm{~mL}$ of enzyme extract. After incubation for $30 \mathrm{~min}$ at $30^{\circ} \mathrm{C}$, the reaction was stopped by adding $2 \mathrm{~mL}$ of $2.5 \%(\mathrm{w} / \mathrm{v}) \mathrm{FeCl}_{3}$ and $5 \%(\mathrm{w} / \mathrm{v})$ trichloroacetic acid in $1.5 \mathrm{M} \mathrm{HCl}$. After centrifugation at $3000 \times \mathrm{g}$ for $10 \mathrm{~min}$, the absorbance of the supernatant at $540 \mathrm{~nm}$ was recorded by a spectrophotometer.

To assay the activity of GDH, the extraction buffer $(\mathrm{pH}$ 7.9) was consisted of $0.05 \mathrm{M}$ imidazole and $5 \mathrm{mM}$ DTT. Fresh leaf samples $(1 \mathrm{~g})$ were ground in liquid nitrogen and then centrifuged at $12000 \times \mathrm{g}$ for $40 \mathrm{~min}$ at $4^{\circ} \mathrm{C}$. The supernatant was used to measure the activity of glutamate dehydrogenase according to the $\operatorname{methods}^{[34]}$

To assay the activity of GOGAT, the extraction buffer contained $10 \mathrm{mM}$ Tris- $\mathrm{HCl}$ (pH 7.6), $1 \mathrm{mM} \mathrm{MgCl} 2,1 \mathrm{mM}$ EDTA, and $1 \mathrm{mM}$ mercaptoethanol. Fresh leaf samples $(2 \mathrm{~g})$ were centrifuged at $12000 \times \mathrm{g}$ for $30 \mathrm{~min}$ at $4^{\circ} \mathrm{C}$. The standard assay mixture was consisted of $40 \mathrm{mM}$ potassium phosphate buffer $(\mathrm{pH}$ 7.5), $10 \mathrm{mM}$ L-glutamine, $10 \mathrm{mM}$ 2-oxoglutarate, $0.14 \mathrm{mM} \mathrm{NADH}$, and crude enzyme (final volume of $3 \mathrm{~mL}$ ). The increase in absorbance was recorded at $340 \mathrm{~nm}$ for 3-4 min at room temperature $\left(25^{\circ} \mathrm{C}\right)$.

\subsection{Measurement of soil nitrate nitrogen}

At sowing silking and harvest, four soil samples per plot were taken using an auger. In 2018, soil samples to a depth of $60 \mathrm{~cm}$ at $20 \mathrm{~cm}$ increments were taken. Soil samples were extracted using $0.01 \mathrm{~mol} / \mathrm{L} \mathrm{CaCl}{ }_{2}$ and analyzed for $\mathrm{NO}_{3}{ }^{-}-\mathrm{N}$ using the continuous flow analysis (TRAACS 2000, Bran and Luebbe, Norderstedt, Germany).

\subsection{Calculation of $\mathrm{N}$-associated traits}

Calculations for leaf $\mathrm{N}$ remobilization and the $\mathrm{N}$ efficiency parameters were determined as the $\mathrm{N}$ content between vegetative and reproductive stages utilizing the next equations ${ }^{[35-37]}$.

Leaf $\mathrm{N}$ remobilization (leaf $\mathrm{RemN}$ ) = leaf $\mathrm{N}$ content at silking - leaf $\mathrm{N}$ content at sample date after silking

Nitrogen utilization efficiency $(\mathrm{NUE})=$ grain yield/plant $\mathrm{N}$ content at maturity.

Nitrogen harvest index $(\mathrm{NHI}, \%)=$ grain $\mathrm{N}$ content/plant $\mathrm{N}$ content at maturity $\times 100$

\subsection{Statistical analysis}

Statistical evaluations were performed using IBM SPSS version 19.0 software. All data in the figures and tables were analyzed by analysis of variance (ANOVA) and were compared using the least significant difference (LSD) test at $p<0.05$ probability level. All figures were constructed using SigmaPlot 10 (Systat Software Inc. San Jose, CA, USA). The relevance relevant analysis was were carried out using the R Studio.

\section{Results and discussion}

\subsection{Grain yield, NUtE and dry matter accumulation}

Significant differences were found in grain yield, kernel numbers, NtUE and NHI between the two maize cultivars, whereas no significant differences in the ear numbers and 100-grains weights. Grain yield, kernel numbers, NUtE and NHI were higher in ZD958 than that in HN138 (Tables 1 and 2). Across all N rates, the grain yields were higher than those in $\mathrm{HN} 138$ by $2.28 \mathrm{t} / \mathrm{hm}^{2}$ and $2.56 \mathrm{t} / \mathrm{hm}^{2}$ in 2017 and 2018, respectively, this due to the higher kernel numbers. The year had significant effects on kernel numbers, NUE and NHI, but not on grain yield. Kernel numbers was higher in 2017 than 2018, while NUE and NHI were higher in 2018 than 2017. N rate had significant effects on grain yield, kernel numbers, NUE and NHI, nitrogen-deficiency (N120 and N0) stress decreased grain yield, kernel numbers, NUE and NHI.

No significant difference was found in dry matter accumulation at before-silking between two maize cultivars (Figure 2), whereas the dry matter accumulation at post-silking and maturity stage showed significant difference between ZD958 and HN138, and the two parameters significantly affected by the year and the values in 2017 higher than that in 2018. The dry matter accumulation at maturity stage of ZD958 were higher than that in HN138, this due to the higher dry matter accumulation at post-silking stage. In 2017 year, the dry matter accumulation at post-silking and maturity stage in ZD958 were higher $6.19 \%$ and $7.68 \%$ than those in HN138 
under high-N rate (N240), whereas higher $10.41 \%$ and $8.60 \%$ than those in HN138 under low-N rate (N120). Similarly results showed that in 2018 year, the dry matter accumulation at post-silking and maturity stage in ZD958 were higher $2.45 \%$ and $3.98 \%$ than those in HN138 under high-N rate (N240), whereas higher $2.03 \%$ and $3.96 \%$ than those in HN138 under low-N rate (N120). These results suggest that ZD958 possess higher dry matter accumulation at post-silking stage under low-N condition.

\subsection{Genotypic variation in leaf photosynthetic parameters}

Significant differences were found in leaf area index and Pn between cultivar $(\mathrm{H})$, nitrogen $(\mathrm{N})$ and sample date $(\mathrm{S})$ and the interaction of $\mathrm{H} \times \mathrm{N}, \mathrm{S} \times \mathrm{N}$ (Table 3). The significant differences were found in leaf area index and Pn between the two maize cultivars and three $\mathrm{N}$ rates (Figure 3), whereas no significant differences in the ear numbers and 100-grains weights. Leaf area index and Pn were higher in ZD958 than that in HN138 each N rates and sample dates. The leaf area index decreased significantly from 0 DAS to 50 DAS. The effect of cultivar and N rate on the leaf area index was significant. The leaf area index of ZD958 was higher than that of HN138 across two years. In 2017 year, from silking (0 DAS) to maturity (50 DAS), the leaf area index of ZD958 and HN138 decreased by $25.18 \%$ and $18 \%$ under high-N rate (N240), decreased by $27.29 \%$ and $27.78 \%$ under low-N rate (N120). Similarly results showed that in 2018 year, the leaf area index of ZD958 and HN138 decreased by $25.96 \%$ and $19.43 \%$ under high- $\mathrm{N}$ rate $(\mathrm{N} 240)$, decreased by $20.71 \%$ and $34.17 \%$ under low-N rate (N120). ZD958 rapid down leaf senescence after silking under high-N rate (N240) and slows down leaf senescence after silking under low-N rate (N120), but ZD958 possess higher leaf area index in the whole grain-filling period in two years.

Table 1 Effects of nitrogen supply on grain yield and its components of ZD958 and HN138 in 2017 and 2018

\begin{tabular}{|c|c|c|c|c|c|c|c|c|}
\hline Year & $\mathrm{N}$ rate & Cultivar & Grain yield/t. hm ${ }^{-2}$ & Ear numbers $/ 10^{4}$ ears $\cdot \mathrm{hm}^{-2}$ & Kernels numbers & 100-grains weights/g & $\mathrm{NUE} / \mathrm{kg} \cdot \mathrm{kg}^{-1}$ & $\mathrm{NHI} / \%$ \\
\hline \multirow{6}{*}{2017} & \multirow{2}{*}{$\mathrm{N} 240$} & ZD958 & $11.17 \mathrm{a}$ & $6.67 \mathrm{a}$ & $530.89 a$ & $31.58 \mathrm{a}$ & $57.25 \mathrm{a}$ & $72.66 a$ \\
\hline & & HN138 & $10.25 b$ & $6.66 \mathrm{a}$ & $477.44 b$ & $34.24 \mathrm{a}$ & $55.99 \mathrm{~b}$ & $68.55 b$ \\
\hline & \multirow{2}{*}{ N120 } & ZD958 & $10.18 \mathrm{a}$ & $6.46 \mathrm{a}$ & $520.91 \mathrm{a}$ & $30.27 \mathrm{a}$ & $70.31 \mathrm{a}$ & $76.16 \mathrm{a}$ \\
\hline & & HN138 & $9.08 \mathrm{~b}$ & $6.31 \mathrm{a}$ & $449.24 b$ & $30.15 \mathrm{a}$ & $68.99 b$ & $70.49 b$ \\
\hline & \multirow{2}{*}{ No } & ZD958 & $9.21 \mathrm{a}$ & $6.41 \mathrm{a}$ & $479.62 \mathrm{a}$ & $29.95 \mathrm{a}$ & $75.09 \mathrm{a}$ & $79.98 \mathrm{a}$ \\
\hline & & HN138 & $7.95 \mathrm{~b}$ & $6.05 \mathrm{~b}$ & $417.31 b$ & $31.51 \mathrm{a}$ & $70.26 \mathrm{~b}$ & $70.09 b$ \\
\hline \multirow{6}{*}{2018} & \multirow{2}{*}{$\mathrm{N} 240$} & ZD958 & $11.97 \mathrm{a}$ & $6.36 \mathrm{a}$ & $527.47 \mathrm{a}$ & $35.67 \mathrm{a}$ & $64.87 \mathrm{a}$ & $78.21 \mathrm{a}$ \\
\hline & & HN138 & $11.24 \mathrm{a}$ & $6.18 \mathrm{a}$ & $495.52 b$ & $36.01 \mathrm{a}$ & $59.80 \mathrm{~b}$ & $73.91 b$ \\
\hline & \multirow{2}{*}{ N120 } & ZD958 & $10.40 \mathrm{a}$ & $6.03 \mathrm{a}$ & $515.27 \mathrm{a}$ & $33.51 \mathrm{a}$ & $77.23 \mathrm{a}$ & $78.00 \mathrm{a}$ \\
\hline & & HN138 & $9.01 \mathrm{~b}$ & $5.67 \mathrm{~b}$ & $492.97 \mathrm{~b}$ & $35.29 \mathrm{a}$ & $72.24 b$ & $72.44 \mathrm{~b}$ \\
\hline & \multirow{2}{*}{ No } & ZD958 & $10.16 \mathrm{a}$ & $5.83 \mathrm{a}$ & $510.68 \mathrm{a}$ & $34.12 \mathrm{a}$ & $83.20 \mathrm{a}$ & $76.20 \mathrm{a}$ \\
\hline & & HN138 & $8.72 b$ & $5.58 \mathrm{~b}$ & $480.37 b$ & $35.06 \mathrm{a}$ & $79.21 \mathrm{~b}$ & $72.46 \mathrm{~b}$ \\
\hline \multicolumn{9}{|c|}{ Analysis of variance } \\
\hline \multicolumn{3}{|c|}{ Year (Y) } & NS & $*$ & $*$ & NS & $*$ & NS \\
\hline \multicolumn{3}{|c|}{ Cultivar (C) } & $* *$ & NS & $* *$ & NS & $*$ & $*$ \\
\hline \multicolumn{3}{|c|}{ Nitrogen $(\mathrm{N})$} & $* *$ & $*$ & $* *$ & NS & $* *$ & NS \\
\hline \multicolumn{3}{|c|}{$\mathrm{Y} \times \mathrm{C}$} & NS & NS & $*$ & NS & $*$ & NS \\
\hline \multicolumn{3}{|c|}{$\mathrm{Y} \times \mathrm{N}$} & NS & NS & NS & NS & NS & NS \\
\hline \multicolumn{3}{|c|}{$\mathrm{C} \times \mathrm{N}$} & NS & NS & NS & NS & NS & NS \\
\hline \multicolumn{3}{|c|}{$\mathrm{Y} \times \mathrm{C} \times \mathrm{N}$} & NS & NS & NS & NS & NS & NS \\
\hline
\end{tabular}

Note: N240, N120 and N0 indicate 240, 120 and $0 \mathrm{~kg} \mathrm{~N} \mathrm{ha}^{-1}$, respectively. The values followed by different lowercase letters in a column are significantly different at the 0.05 level; ${ }^{* *} p<0.01 ;{ }^{*} p<0.05$; NS means insignificant.

Table 2 Analysis of variance of years, cultivars and nitrogen rates on LAI, Pn, total N, PNUE and NR, GS, GDH, GAGOT of leaves in ZD958 and HN138

\begin{tabular}{|c|c|c|c|c|c|c|c|c|c|}
\hline Analysis of variance & LAI & $\mathrm{Pn}$ & PNUE & Total N & Rem N & NR & GS & GDH & GAGOT \\
\hline Year $(Y)$ & NS & NS & $*$ & $*$ & $*$ & NS & NS & NS & NS \\
\hline Cultivar (C) & $* *$ & $* *$ & $* *$ & $* *$ & $* *$ & $*$ & $*$ & $*$ & $*$ \\
\hline Nitrogen $(\mathrm{N})$ & $* *$ & $* *$ & $* *$ & $* *$ & $* *$ & $* *$ & $* *$ & $* *$ & $* *$ \\
\hline Sample date (S) & $* *$ & $* *$ & $* *$ & $* *$ & $* *$ & $* *$ & $* *$ & $* *$ & $* *$ \\
\hline $\mathrm{Y} \times \mathrm{C}$ & NS & NS & $*$ & $*$ & $*$ & NS & NS & NS & NS \\
\hline $\mathrm{C} \times \mathrm{N}$ & $* *$ & $* *$ & $*$ & $*$ & $*$ & $* *$ & $* *$ & $* *$ & $* *$ \\
\hline $\mathrm{Y} \times \mathrm{S}$ & NS & NS & NS & NS & NS & NS & NS & NS & NS \\
\hline $\mathrm{S} \times \mathrm{N}$ & $* *$ & $* *$ & $* *$ & $* *$ & $* *$ & $* *$ & $* *$ & $* *$ & $* *$ \\
\hline $\mathrm{Y} \times \mathrm{C} \times \mathrm{N}$ & NS & NS & NS & NS & NS & $\mathrm{NS}$ & NS & NS & NS \\
\hline $\mathrm{Y} \times \mathrm{C} \times \mathrm{S}$ & NS & NS & NS & NS & NS & NS & NS & NS & NS \\
\hline $\mathrm{S} \times \mathrm{C} \times \mathrm{N}$ & NS & NS & NS & NS & NS & NS & NS & NS & NS \\
\hline
\end{tabular}

Note: LAI: leaf area index; Pn: photosynthetic rate; PNUE: photosynthetic nitrogen use efficiency; Rem N: remobilization N; NR: nitrate reductase activity; GS: glutamine synthetase activity;. $\quad{ }^{* *}, p<0.01 ;{ }^{*}, p<0.05$; NS, not significant. 

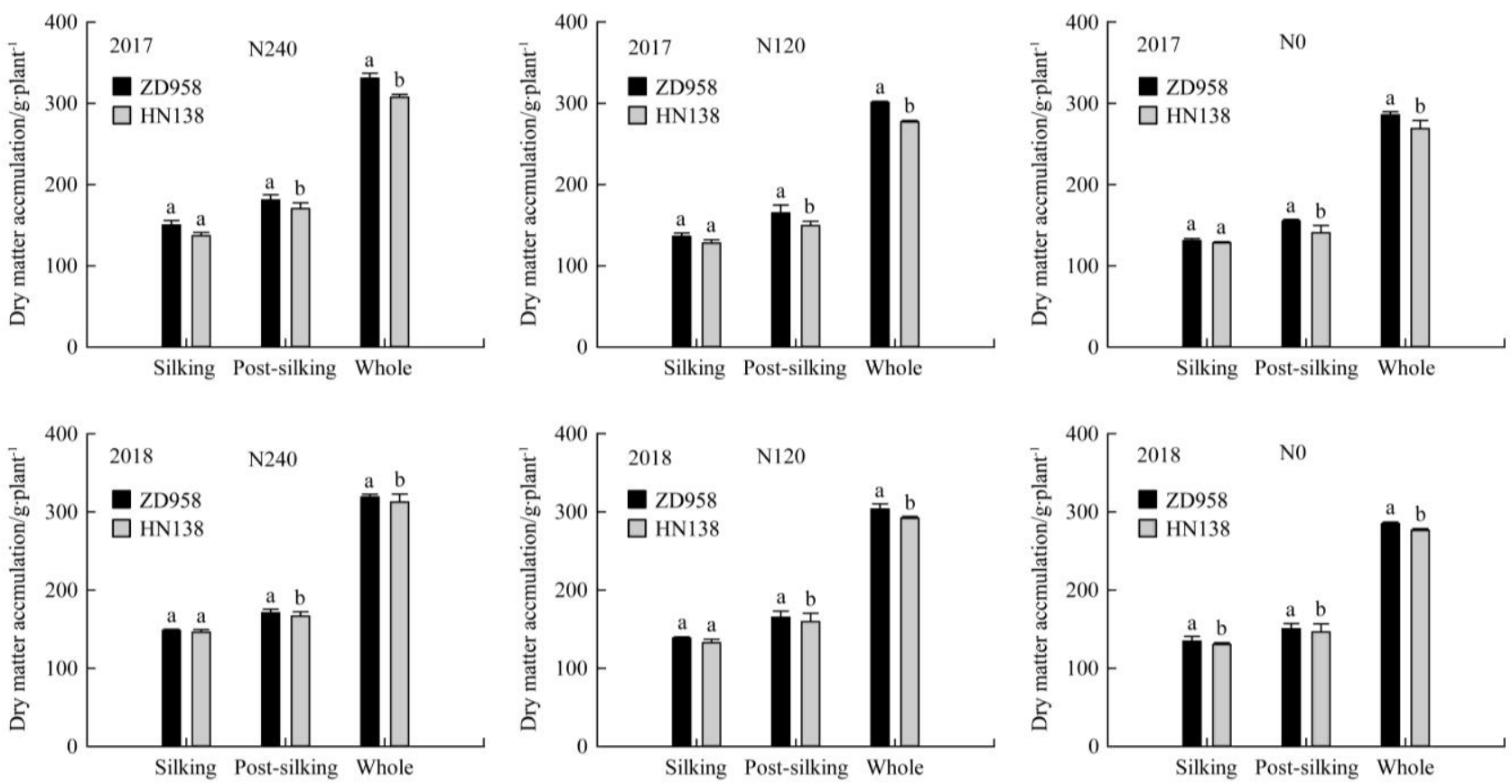

Note: N240, N120 and N0 indicate 240, 120 and $0 \mathrm{~kg} \mathrm{~N} / \mathrm{hm}^{2}$, respectively. The data are presented as the meaNS \pm SEs. The values followed by different lowercase letters are significantly difference at the 0.05 level.

Figure 2 Dry matter accumulation of ZD958 and HN138 under three N rates at the silking, post-silking and whole (maturity) stages
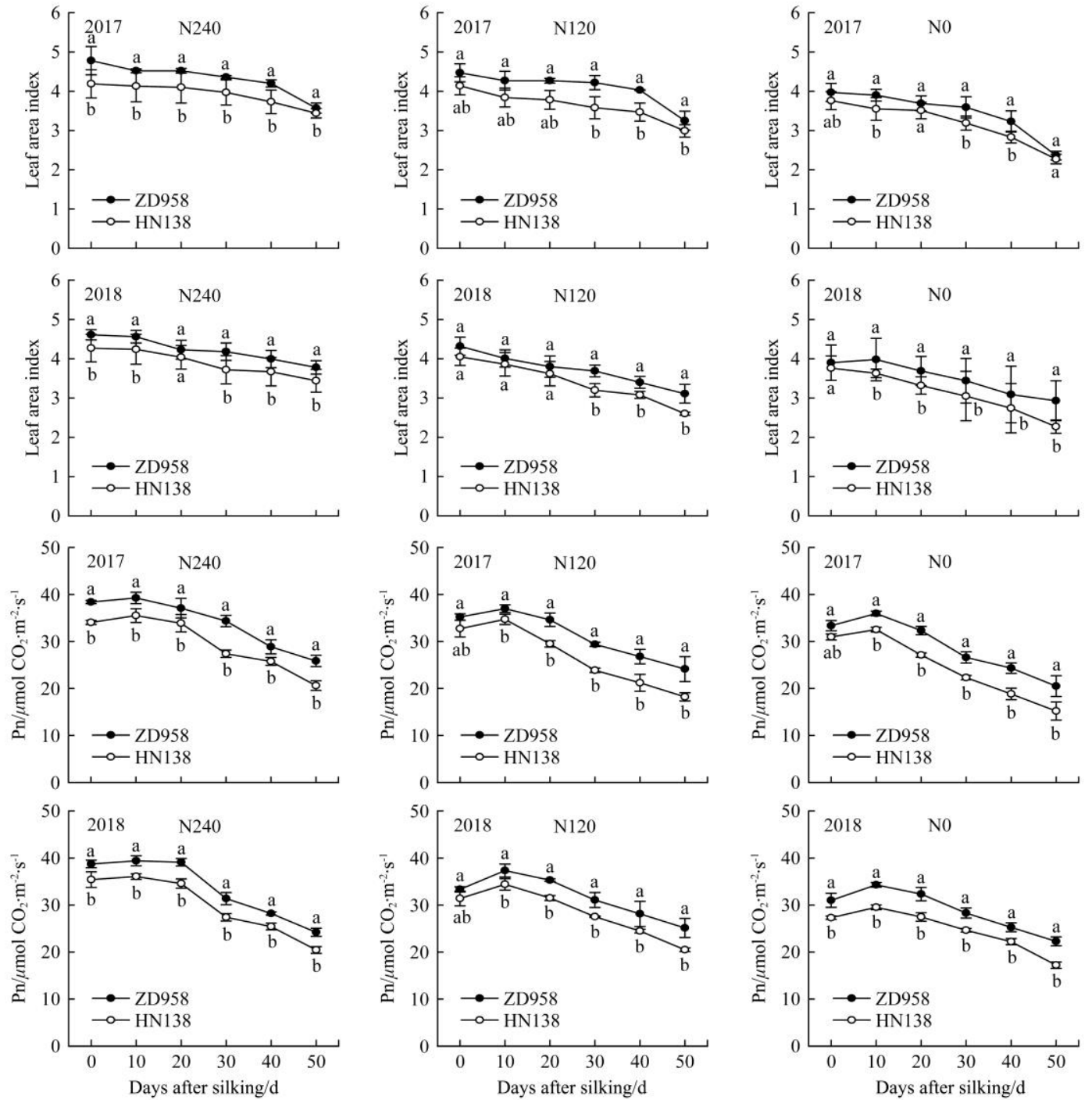

Note: N240, N120 and N0 indicate 240, 120 and $0 \mathrm{~kg} \mathrm{~N} / \mathrm{hm}^{2}$, respectively. The data are presented as the meaNS \pm SEs. The values followed by different lowercase letters are significantly difference at the 0.05 level. Pn: photosynthetic rate.

Figure 3 Leaf area index and Pn in ear-leaf of ZD958 and HN138 under three N rates from silking to 50 DAS 
Table 3 Correlations between leaf Rem N, Pn, PNUE, NR, GS, GDH and GOGAT in maize

\begin{tabular}{lccccccc}
\hline Traits & Rem N & Pn & PNUE & NR & GS & GDH & GOGAT \\
\hline Rem N & - & $-0.51^{* *}$ & $-0.22^{*}$ & $-0.57^{*}$ & $-0.54^{*}$ & $-0.50^{*}$ & $-0.51^{*}$ \\
Pn & & - & $0.80^{* *}$ & $0.62^{*}$ & $-0.54^{*}$ & $-0.52^{*}$ & $-0.54^{*}$ \\
PUNE & & & - & $0.35^{* *}$ & $0.51^{* *}$ & $0.45^{* *}$ & $0.50^{* *}$ \\
NR & & & & - & $0.95^{* *}$ & $0.32^{* *}$ & $0.85^{* *}$ \\
GS & & & & & - & $0.85^{* *}$ & $0.75^{* *}$ \\
GDH & & & & & & - & $0.85^{* *}$
\end{tabular}

GOGAT

Note: Rem N: remobilization N; Pn: photosynthetic rate; PNUE: photosynthetic nitrogen use efficiency; NR: nitrate reductase activity; GS: glutamine synthetase activity; ${ }^{*} p<0.01 ;{ }^{* *} p<0.001$

Similarly, the Pn of ZD958 was greatly increased than that in HN138 in each N treatment and each year (Figure 3). The Pn was higher in ZD958 than HN138 in each N treatment and each year. The Pn was higher in 2017 than 2018. The Pn decreased significantly from 0 DAS to 50 DAS. The Pn of ZD958 was higher than that of HN138. The leaf Pn decreased rapidly at 30 DAS under high- $\mathrm{N}$ rate $(\mathrm{N} 240)$ and decreased rapidly at 20 DAS under low-N rate (N120). For example, in 2018 year, the leaf Pn of ZD958 and HN138 decreased by $19.02 \%$ and $22.60 \%$ at 30 DAS under high-N rate (N240), respectively. The leaf Pn of ZD958 and HN138 decreased by $4.81 \%$ and $9.88 \%$ at 20 DAS under low-N rate (N120), respectively. These results suggest that ZD958 possess higher leaf area index and Pn during grain-filling stage under low-N conditions, this could promote accumulation of more photosynthetic products in leaf.

Post-silking dry matter accumulation is related to Pn, leaf area index and the duration of photosynthetic function. All of these factors are closely correlated to $\mathrm{N}$ content in leaf ${ }^{[10,39]}$. It has been reported that $\mathrm{N}$ translocation decreases leaf area index, chlorophyll content, and photosynthetic rate. The slow decline on chlorophyll content and net photosynthetic rate after silking, together with a longer duration of high photosynthetic activity, is essential for sufficient carbohydrate supplies for grains during the grain-filling stage $^{[10,14,40]}$. This result indicated ZD958 has a higher leaf area index and Pn than does HN138 under all N rates, the leaf area index and Pn of this cultivar declined slowly under low-N conditions, and displayed prolonged high photosynthetic activity (Figure 3). These finding are in consistent with previous results that suggested a sufficient carbohydrate supply to be beneficial for grain filling ${ }^{[10]}$. These results indicated that ZD958 had relative higher green leaf area and possess active photosynthetic under low- $\mathrm{N}$ conditions at grain-filling stage.

\subsection{Genotypic variation in leaf $\mathbf{N}$ contents parameters}

Significant differences were found in leaf $\mathrm{N}$ contents and $\mathrm{N}$ remobilization between year $(\mathrm{Y})$, cultivar $(\mathrm{H})$, nitrogen $(\mathrm{N})$ and sample date $(\mathrm{S})$ and its interaction of $\mathrm{Y} \times \mathrm{N}, \mathrm{Y} \times \mathrm{H}, \mathrm{H} \times \mathrm{N}, \mathrm{S} \times \mathrm{N}$ (Table 3). Significant differences were found in leaf $\mathrm{N}$ contents between the two cultivars and three $\mathrm{N}$ rates (Figure 4). The leaf $\mathrm{N}$ contents decreased significantly from 0 DAS to 50 DAS. The effect of cultivar and $\mathrm{N}$ rate on the leaf $\mathrm{N}$ contents was significant. From 0 DAS to 40 DAS, the leaf total N of ZD958 was higher than that in HN138 (Figure 4), but at 50 DAS, the leaf total N of ZD958 was lower than that in HN138. In 2017 year, from 0 DAS to 50 DAS, the leaf total $\mathrm{N}$ of ZD958 and HN138 decreased by $75.33 \%$ and $63.04 \%$ under high-N rate $(\mathrm{N} 240)$ and decreased by $77.12 \%$ and $68.58 \%$ under low-N rate $(\mathrm{N} 120)$, respectively. Similarly results showed that in 2018 year, the leaf total $\mathrm{N}$ of ZD958 and HN138 decreased by $70 \%$ and $65.34 \%$ under high-N rate $(\mathrm{N} 240)$ and decreased by $74.22 \%$ and $47.27 \%$ under low-N rate (N120), respectively. The leaf $\mathrm{N}$ remobilization occurred at 10 DAS but that there was no significant difference between the two maize cultivars (Figure 4). The difference in leaf $\mathrm{N}$ remobilization between the two cultivars could be observed from 30-40 DAS under high-N rate (N240), the difference occurred 10 days earlier, i.e. from 20-30 days after silking under low-N rate (N120). These results suggest that ZD958 possess higher leaf $\mathrm{N}$ remobilization during grain-filling stage, the higher leaf $\mathrm{N}$ remobilization could promote $\mathrm{N}$ assimilation and utilization.

\subsection{Genotypic variation in leaf PNUE}

Significant differences were found in leaf $\mathrm{N}$ contents and $\mathrm{N}$ remobilization between years $(\mathrm{Y})$, cultivar $(\mathrm{H})$, nitrogen $(\mathrm{N})$ and sample date (S) and its interaction of $\mathrm{Y} \times \mathrm{N}, \mathrm{Y} \times \mathrm{H}, \mathrm{H} \times \mathrm{N}, \mathrm{S} \times \mathrm{N}$ (Table 3). Significant differences were found in leaf PNUE between the two cultivars and three $\mathrm{N}$ rates (Figure 4). From 0 DAS to 30 DAS, the leaf PNUE of ZD958 was similar with HN138 under same N treatment and same years, but from 30 DAS to 50 DAS, the leaf PNUE of ZD958 was higher than that in HN138 (Figure 4). The PNUE of ear-leaf was higher in 2018 than 2017. The PNUE of ear-leaf decreased significantly from 0 DAS to 50 DAS. In 2017 year, from 0 DAS to 50 DAS, the PNUE of ear-leaf in ZD958 and HN138 decreased by $19.22 \%$ and $27.60 \%$ under high-N rate $(\mathrm{N} 240)$ and decreased by $18.71 \%$ and $35.24 \%$ under low-N rate (N120), respectively. In 2018 year, from 0 DAS to 50 DAS, the leaf PNUE of ZD958 and HN138 decreased by $15.68 \%$ and $13.17 \%$ under high-N rate $(\mathrm{N} 240)$ and decreased by $16.25 \%$ and $23.48 \%$ under low-N rate (N120), respectively. These results suggest that ZD958 possess higher leaf PNUE during grain-filling stage, could accumulate more amounts of nitrogen per unit area.

The PNUE of leaves is defined as the photosynthetic capacity per unit leaf $\mathrm{N}$ amount and is controlled by SLN and Pn which are determined by stomatal and non-stomatal factors, largely affected by the allocation of leaf $\mathrm{N}$ to photosynthetic and non-photosynthetic proteins ${ }^{[1,42]}$. When compared to HN138, the generally higher PNUE of ZD958 across years and sampling dates is likely related to its higher Pn (Figure 4). This result also showed that ZD958 exhibited higher leaf N remobilization and Pn during the grain-filling stage under low-N conditions, which ensure a high-level accumulation of photosynthetic products and leaf $\mathrm{N}$ remobilization to maintain grain yields and $\mathrm{N}$ concentration. This maybe ZD958 could maintain a high photosynthetic rate when $\mathrm{N}$ was translocated from the leaves to the grain. PUNE is affected by the proportion of nitrogen involved in photosynthetic and photosynthetic enzyme activity in the leaves ${ }^{[43]}$. The proper application of nitrogen fertilizer is helpful for increasing the leaf PUNE, which could increase the yield of maize ${ }^{[44,45]}$. This result indicated that under low-N conditions, enhancement of post-silking dry matter accumulation and grain yield is important to improve the leaf PUNE, prolong photosynthetic function, and improve the premature senescence of leaves.

\subsection{Genotypic variation in $\mathrm{N}$ assimilation enzymes activities}

The $\mathrm{N}$ assimilation enzymes activities in ear-leaf were further examined. Significant differences were found in $\mathrm{N}$ assimilation enzymes activities between year $(\mathrm{Y})$, cultivar $(\mathrm{H})$, nitrogen $(\mathrm{N})$ and sample date (S) and its interaction of $\mathrm{H} \times \mathrm{N}, \mathrm{S} \times \mathrm{N}$ (Table 3). The $\mathrm{N}$ assimilation enzymes activities, nitrate reductase (NR) activity, glutamine synthetase activity (GS), glucose dehydrogenase activity 
(GDH) and glutamate synthase activity (GOGAT) were higher in 2017 than those in 2018. The values in ZD958 increased significantly compared to that in HN138 under all $\mathrm{N}$ rates during the sampling period (Figure 5). Furthermore, The $\mathrm{N}$ assimilation enzymes activities increased slowly from 0 DAS to 20DAS or 30 DAS, decreased rapidly beginning at 30 DAS under high-N rate (N240). Whereas decreased rapidly beginning at 20 DAS under low-N rate (N120 and N0).
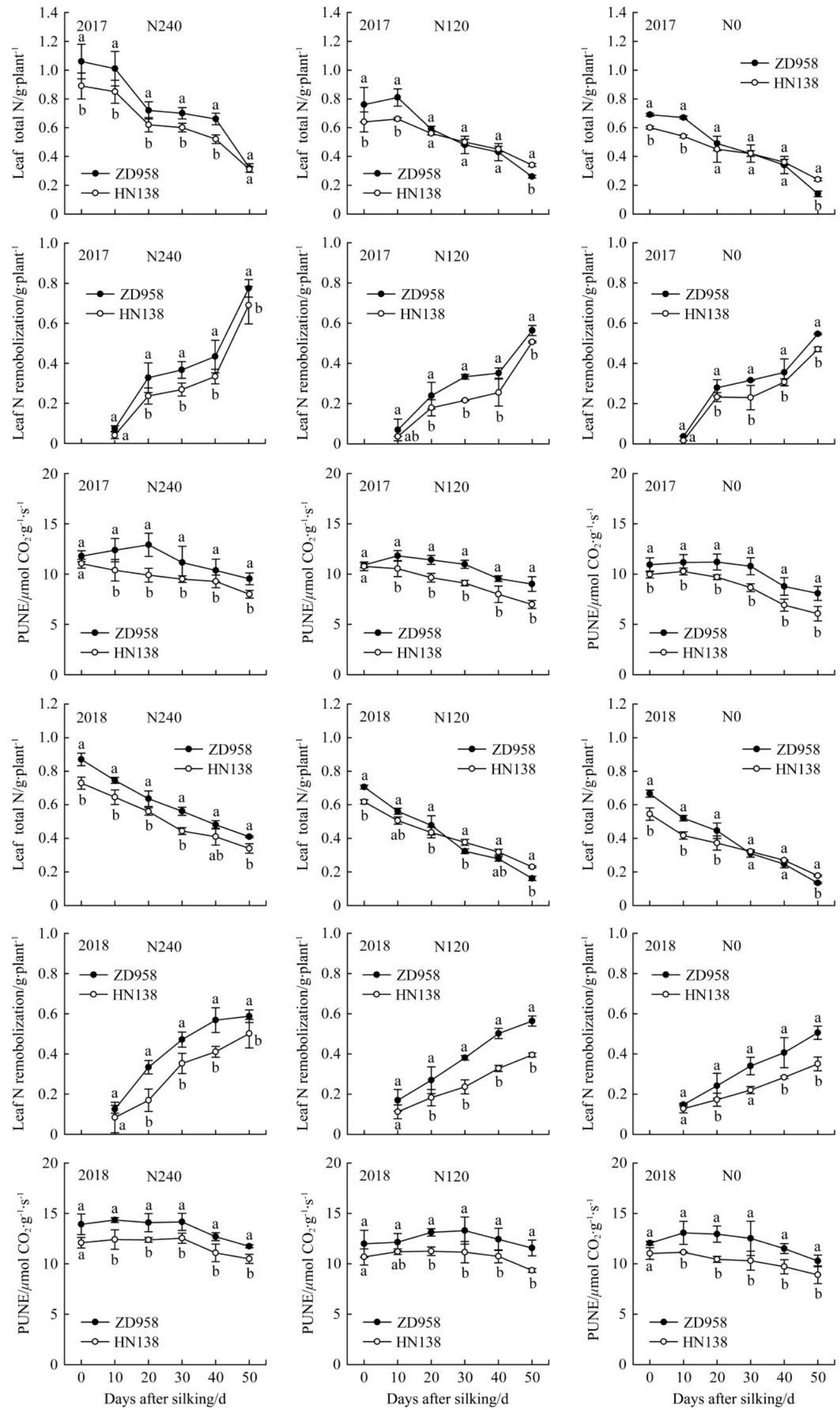

Note: N240, N120 and N0 indicate 240, 120 and $0 \mathrm{~kg} \mathrm{~N} / \mathrm{hm}^{2}$, respectively. The data are presented as the mean value \pm SEs. The values followed by different lowercase letters are significantly difference at the 0.05 level. Rem N: remobilization N; PNUE: photosynthetic nitrogen use efficiency.

Figure 4 Leaf total N, remobilized N and PNUE of ZD958 and HN138 under three N rates from silking to 50 DAS 

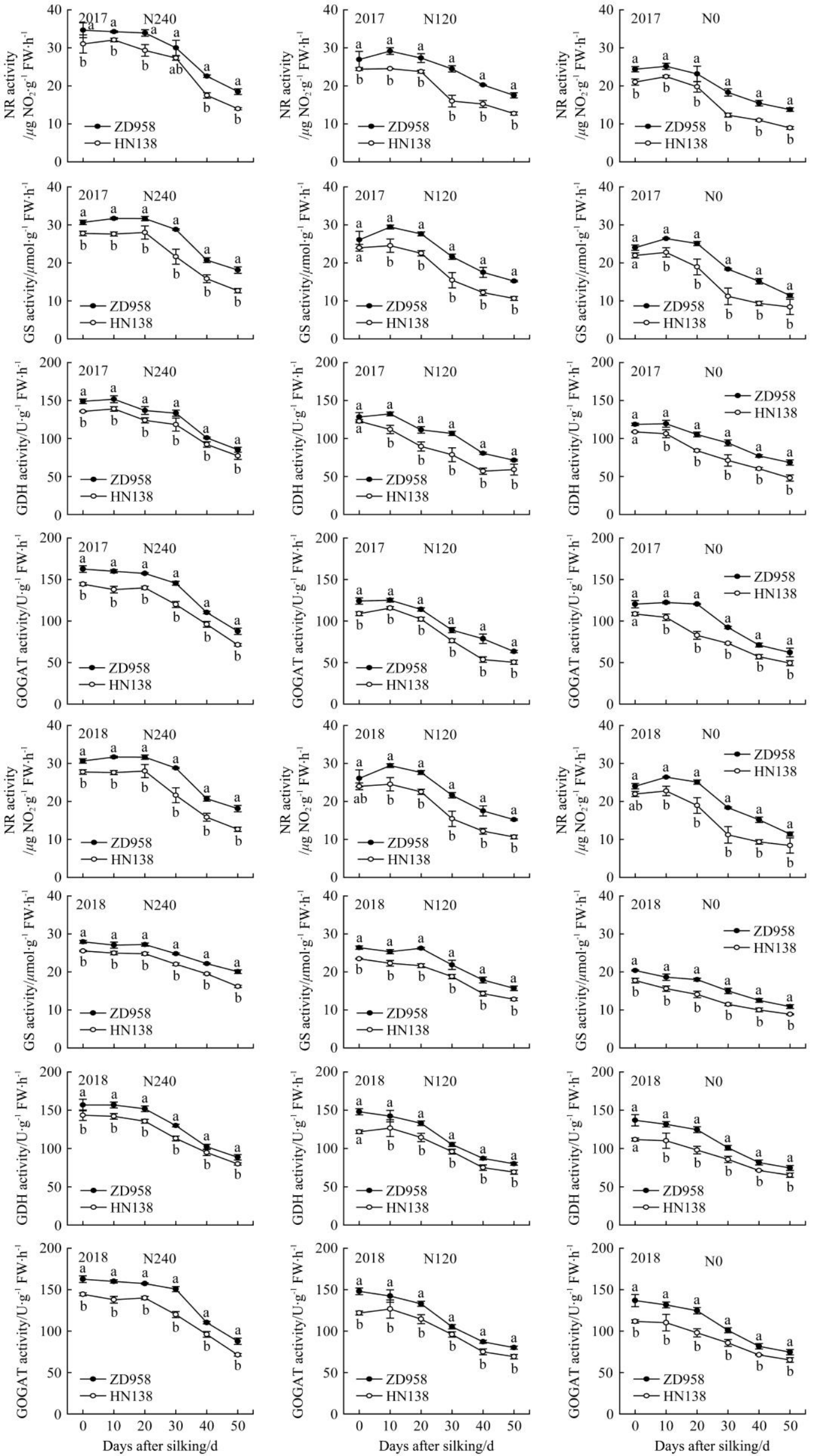

The values followed by different lowercase letters are significantly difference at the 0.05 level. NR: nitrate reductase activity; GS: glutamine synthetase activity; GDH: glucose dehydrogenase activity; GOGAT: glutamate synthase activity.

Figure 5 Leaf NR, GS ,GDH and GAOT activities in ear-leaf of ZD958 and HN138 under three N rates from silking to 50 DAS 
Under low-N rate (N120 and N0), the NR activities in ZD958 and HN138 decreased by $17.05 \%$ and $35.66 \%$ at 20 DAS in 2017, respectively, and decreased by $10.05 \%$ and $25.36 \%$ at 20 DAS in 2018, respectively. Similarly results showed that, the GS activities in ZD958 and HN138 decreased by $20.71 \%$ and $22.16 \%$ in 2017 at 20 DAS under low-N rate (N120), respectively. Whereas, the two maize cultivars decreased by $22.01 \%$ and $25.21 \%$, respectively at 20 DAS in 2018. Similarly results showed that in the GDH and GOGAT activities in ear-leaf between ZD958 and HN138. These results suggest that ZD958 possess higher leaf NR, GS, GDH and GOGAT activities during grain-filling stage, the higher enzymes activities involved in nitrogen assimilation of ear-leaf could promote $\mathrm{N}$ assimilation and utilization.

Glutamine synthetase (GS)/glutamate synthase (GOGAT) cycle is a main pathway of nitrogen assimilation and conversion route for the conversion of inorganic nitrogen to organic nitrogen ${ }^{[46]}$. Previous studies have shown that genotypes with high NUE exhibit relatively increased amounts of leaf nitrate reductase and glutamine synthetase activity ${ }^{[47,48]}$. The glutamine synthetase activity, and total nitrogen contents in low-N tolerant cultivars are higher than those in low-N sensitive cultivars ${ }^{[48]}$. This study showed that the GS activity of leaf in ZD958 was higher than HN138 under low-N conditions (Figure 5). Moreover, the higher GS activity of leaf was maintained at the late grain-filling stage, suggesting that ZD958 exhibited a strong capability of $\mathrm{N}$ assimilation and remobilization with high $\mathrm{N}$ uptake and storage. The GDH is an enzyme capable of catalyzing glutamate de-amination as well as glutamate synthesis, carries out the de-amination reaction in source leaves ${ }^{[22]}$. It has also been shown that GOGAT is still functional in senescing leaves and can participate in glutamate synthesis. In this case, the origin of 2-oxoglutarate and reducing power remains to be determined. This study showed that the GDH and GOGAT activity of leaf in ZD958 was higher than HN138 under low-N conditions (Figure 5). Moreover, the higher GDH and GOGAT activity of leaf was maintained at the late grain-filling stage, suggesting that ZD958 exhibited a strong capability of $\mathrm{N}$ assimilation and remobilization with high $\mathrm{N}$ uptake and storage, which was consistent with previous study results ${ }^{[22]}$.

\subsection{Soil nitrate concentrations}

To determine if the change of soil nitrate depletion, nitrate concentration in the soil profile was investigated. There were no significant differences between the genotypes at the sowing stage. But the soil nitrate concentrations at the silking and harvest stage were higher in ZD958 than HN138. There was high variability in soil nitrate levels in three treatments among ZD958. Under the N240 treatment (Table 4), there were no significant differences between the genotypes. Under the N120 treatment, the soil nitrate concentration in HN138 declined in the 0-60 cm layer compared with ZD958.

\subsection{Correlations between $\mathrm{N}$ remobilization, photosynthetic} rate and $N$ assimilation enzymes activity

The correlations between $\mathrm{N}$ remobilization, photosynthetic rate and enzyme activities involved in $\mathrm{N}$ assimilation were examined (Table 3). A significant correlation coefficient between Rem N, Pn, PNUE and NR, GS, GDH and GOGAT. Among these correlations, a significant negative correlation was found between Rem N and Pn, PNUE, and NR, GS, GDH, GOGAT. These results indicated that the increased leaf nitrogen remobilization led to a decrease in other factors. The PNUE was significantly and positively correlated with NR, GS, GDH, GOGAT suggesting that
PNUE and NR, GS, GDH, GOGAT jointly determined the nitrogen remobilization efficiency and the leaf $\mathrm{N}$ remobilization during post-silking.

Table 4 Soil nitrate concentrations in ZD958 and HN138 under different $\mathbf{N}$ treatments in 2018

\begin{tabular}{|c|c|c|c|c|c|}
\hline \multirow{2}{*}{ Cultivars } & \multirow{2}{*}{$\mathrm{N}$ treatment } & \multirow{2}{*}{$\begin{array}{l}\text { Soli depth } \\
\text { /cm }\end{array}$} & \multicolumn{3}{|c|}{ Soil nitrate concentrations $/ \mathrm{mg} \cdot \mathrm{kg}^{-1}$} \\
\hline & & & Sowing & Silking & Harvest \\
\hline \multirow{9}{*}{ ZD958 } & \multirow{3}{*}{$\mathrm{N} 240$} & $0-20$ & 34.45 & 69.22 & 49.38 \\
\hline & & $20-40$ & 29.25 & 52.64 & 17.13 \\
\hline & & $40-60$ & 21.00 & 36.01 & 12.04 \\
\hline & \multirow{3}{*}{ N120 } & $0-20$ & 30.38 & 46.43 & 28.95 \\
\hline & & $20-40$ & 25.84 & 42.32 & 12.37 \\
\hline & & $40-60$ & 18.92 & 30.47 & 10.21 \\
\hline & \multirow{3}{*}{ No } & $0-20$ & 29.34 & 36.76 & 30.28 \\
\hline & & $20-40$ & 24.78 & 27.03 & 14.39 \\
\hline & & $40-60$ & 17.68 & 25.85 & 8.65 \\
\hline \multirow{9}{*}{ HN138 } & \multirow{3}{*}{$\mathrm{N} 240$} & $0-20$ & 34.32 & 57.92 & 44.89 \\
\hline & & $20-40$ & 29.32 & 41.34 & 18.31 \\
\hline & & $40-60$ & 20.00 & 24.71 & 8.68 \\
\hline & \multirow{3}{*}{ N120 } & $0-20$ & 27.38 & 35.13 & 7.99 \\
\hline & & $20-40$ & 24.30 & 31.02 & 13.99 \\
\hline & & $40-60$ & 17.92 & 22.17 & 6.14 \\
\hline & \multirow{3}{*}{ No } & $0-20$ & 26.34 & 25.46 & 4.70 \\
\hline & & $20-40$ & 23.00 & 21.73 & 11.70 \\
\hline & & $40-60$ & 16.68 & 17.55 & 1.52 \\
\hline
\end{tabular}

Leaf N remobilization is negatively correlated to PNUE and all the $\mathrm{N}$ assimilation enzymes (Table 3). The high Pn of ZD958 is consistent with its higher leaf area index, PNUE and $\mathrm{N}$ assimilation enzyme, but also inconsistent with its $\mathrm{N}$ remobilization in leaves (Table 3). This is in agreement with the study results ${ }^{[1]}$, who found that although modern maize stay-green high-yield breeding significantly increased the green leaf area and the $\mathrm{N}$ content of leaves. The PNUE may be improved, if the $\mathrm{N}$ of leaves is channeled into the critical limiting photosynthetic proteins ${ }^{[49]}$ to enhance their efficiency ${ }^{[50]}$. Enhance the NR and GS activity of leaf could contribute to possess higher PNUE, this due to the increased GS activity can improve nitrogen remobilization efficiency and nitrogen assimilation efficiency ${ }^{[27,51]}$.

\section{Conclusions}

In this study, the analysis of two maize cultivars with contrasting low-N tolerant revealed that, to simultaneously achieve high grain yield and high NUtE, a maize cultivar should maintain the higher PNUE while increasing the $\mathrm{N}$ assimilation enzyme activity of the ear-leaf during the grain-filling stage. Firstly, it is worth mentioning that enhance GS activity can improve $\mathrm{N}$ remobilization and assimilation, this is an important physiological mechanism of high NUtE in maize. In addition, the PNUE was significantly and positively correlated with NR, GS, GDH, GOGAT, suggesting that the PNUE and NR, GS, GDH, GOGAT jointly determined the leaf $\mathrm{N}$ remobilization. The plant traits comprising a higher PNUE and $\mathrm{N}$ assimilation enzyme activities of the ear-leaf can be used as selection criteria to select low-N tolerance cultivars for growth under low-N conditions. Finally, this investigation provides insights into the $\mathrm{N}$-associated physiological processes that maize species responds to $\mathrm{N}$ deprivation and puts forward guidance for breeding low-N tolerant and high NUE maize cultivars under low-N conditions. 


\section{Acknowledgements}

This work was supported by the National Key Research and Development Program of China (No. 2018YFD0300503). We gratefully acknowledge Jianhang Jia and Wei Ma for revising the manuscript. We also sincerely thank the reviewers for the critical comments on our original manuscript.

\section{[References]}

[1] Chen X C, Chen F J, Gao Q, Yang X L, Yuan L X, Zhang F S, et al. Modern maize cultivars in Northeast China exhibit increased yield potential and resource use efficiency despite adverse climate change. Global Change Biology, 2013; 19: 923-936.

[2] Emmanuel A A, Chai Q, Jeffrey A. Mechanisms of nitrogen use in maize. Agronomy, 2019; 9: 775

[3] Moll R H, Kamprath E J, Jackson W A. Analysis and interpretation of factors which contribute to efficiency of nitrogen utilization. Agronomy Journal, 1982; 74: 562-568.

[4] Kant S, Bi Y M, Rothstein S J. Understanding plant response to nitrogen limitation for the improvement of crop nitrogen use efficiency. Journal of Experimental Botany, 2011; 62: 1490-1509.

[5] Bingham I J, Karley A J, White P J, Thomas W T B, Russell J R. Analysis of improvements in nitrogen use efficiency associated with 75 years of spring barley breeding. European Journal of Agriculture, 2012; 42: 49-58.

[6] Wu Q P, Chen F J, Chen Y L, Yuan L X, Zhang F S, Mi G H. Root growth in response to nitrogen supply in Chinese maize cultivars released between 1973 and 2009. Science China Life Sciences, 2011; 54: 642-650

[7] Wu Y S, Liu W G, Li X H, Li M S, Zhang D G, Hao Z F, et al. Low-nitrogen stress tolerance and nitrogen agronomic efficiency among maize inbreds: comparison of multiple indices and evaluation of genetic variation. Euphytica, 2011; 180: 281-290

[8] Chen Y L, Wu D L, Mu X H, Xiao C X. Vertical distribution of photosynthetic nitrogen use efficiency and its response to nitrogen in field-grown maize. Crop. Science, 2016; 56: 397-407.

[9] Martínez D E, Costa M L, Guiamet J J. Senescenceassociated degradation of chloroplast proteins inside and outside the organelle. Plant Biology, 2008; 10: 15-22.

[10] Ning P Li, S Yu P, Zhang Y Li, C J. Post-silking accumulation and partitioning of dry matter, nitrogen, phosphorus and potassium in maize varieties differing in leaf longevity. Field Crop Research, 2013; 144: $19-27$.

[11] Yan P, Yue S, Qiu M, Chen X, Cui Z, Chen F. Using maize cultivars and in-season nitrogen management to improve grain yield and grain nitrogen concentrations. Field Crop Research, 2014; 166: 38-45

[12] Chang J F., Dong P F, Wang X L, Liu W L, Li C H. Effect of nitrogen application on carbon and nitrogen metabolism of different summer maize varieties. Science Agricultural Science, 2017; 50: 2282-2293.

[13] Valentinuz O R, Matthijs T. Vertical profile of leaf senescence during the grain-filling period in older and newer maize cultivars. Crop Science, 2004; 44: 827-834

[14] Li Q, Ma X J, Chen Q B, Dou P, Yu DH, Luo Y Q, et al. Effects of nitrogen fertilizer on post-silking dry matter production and leaves function characteristics of low-nitrogen tolerance maize. Chinese Journal of Ecological-Agriculture, 2016; 24: 17-26.

[15] Wu Y W, Li Q. Effect of low-nitrogen stress on photosynthesis and chlorophyll fluorescence characteristics of maize cultivars with different low nitrogen tolerances. Journal of Integrative Agriculture, 2019; 18: $1246-1256$

[16] Su W, Kamran M, Xie J, Meng X, Han Q, Liu T, Han J. Shoot and root traits of summer maize cultivar varieties with higher grain yields and higher nitrogen use efficiency at low nitrogen application rates. PeerJ, 2019; 7: e7294.

[17] Masclaux C, Quillere I, Gallais A, Hirel B. The challenge of remobilization in plant nitrogen economy. A survey of physioagronomic and molecular approaches. Annals of Applied Biology, 2001; 138: 68-81.

[18] Buchanan W V, Earl S, Harrison E, Mathas E, Navabpour S, Page T, et al. The molecular analysis of leaf senescence-a genomics approach. Plant Biotechnology Journal, 2003; 1: 3-22

[19] Tercé-Laforgue T, Mack G, Hirel B. New insights towards the function of glutamate dehydrogenase revealed during source-sink transition of tobacco (Nicotiana tabacum L.) plants grown under different nitrogen regimes. Physiology Plant, 2004; 120: 220-228

[20] Gallais A, Hirel B. An approach of the genetics of nitrogen use efficiency in maize. Journa.1 Exerimental Botony, 2004; 396: 295-306

[21] Hirel B, Martin A, Tercé-Laforgue T, Gonzalez-Moro M B, Estavillo J M. Physiology of maize I: a comprehensive and integrated view of nitrogen metabolism in a C4 plant. Physiology Plant, 2005; 124: 167-177.

[22] Masclaux D C, Reisdorf C M, Pageau K., Lelandais M, Grandjean O, Kronenberger $\mathrm{J}$, et al. Glutamine synthetase-glutamate synthase pathway and glutamate dehydrogenase play distinct roles in the sink-source nitrogen cycle in tobacco. Plant. Physiology, 2006; 140: 444-456

[23] Hirel B, Bertin P, Quillere I, Bourdoncl W, Attagnant C, Dellay C, et al Towards a better understanding of the genetic and physiological basis for nitrogen use efficiency in maize. Plant Physiology, 2001; 125: 1258-1270.

[24] Liu P, Wu A L, Wang J S, Nan J K., Dong E W, Jiao X Y, et al. Nitrogen Use Efficiency and physiological responses of different sorghum genotypes influenced by nitrogen deficiency. Scientia Agricultura Sinica, 2018; 51: 3074-3083.

[25] Prester T, Groh S, Landbech M, Seitz G. Nitrogen uptake and utilization efficiency of European maize cultivars developed under conditions of low and high nitrogen input. Plant Breeding, 2010; 121: 480-486.

[26] Xiong S P, Wu K Y, Wang X C, Zhang J, Du P, Wu Y X, et al. Analysis of root absorption characteristics and nitrogen utilization of wheat genotypes with different N efficiency. Scientia Agricultura Sinica, 2016; 49: $2267-2279$.

[27] Shah J M, Bukhari S A H, Zeng J B, Quan X Y, Ali E, Muhammad N, et al. Nitrogen $(\mathrm{N})$ metabolism related enzyme activities, cell uitrastructure and nutrient contents as affected by $\mathrm{N}$ level and barley genotype. Journal of Integrative Agriculture, 2017; 1: 194-202.

[28] Li X L, Guo L G, Zhou B Y, Tang X M, Chen C C, Zhang L, et al Characterization of low-N responses in maize (Zea mays L.) cultivars with contrasting nitrogen use efficiency in the North China Plain. Journal of Integrative Agriculture, 2019; 18(9): 2141-2152.

[29] Han J N, Wang L F, Zheng H Y, Pan X Y, L X, Chen F J, et al. ZD958 is a low-nitrogen-efficient maize cultivar at the seedling stage among five maize and two teosinte lines. Planta, 2015; 242(4): 1-16.

[30] Neal D O, Joy K W. Glutamine synthetase of pea leaves: Purification, stabilization and $\mathrm{pH}$ optima. Archives of biochemistry and biophysics, 1973; 159: 113-122.

[31] Lu D J, Yue S C, Lu F F, Cui Z L, Liu Z H, Zou C Q, et al. Integrated crop-N system management to establish high wheat yield population. Field Crops Research, 2016; 191: 66-74.

[32] Chen G P, Yang G H, Zhao M, Wang L C, Wang Y D, Xue J Q, et al. Studies on maize small area super-high yield trails and cultivation technique. Journal of Maize Science, 2008; 16: 1-4.

[33] Meng Q F, Sun Q P, Chen X P, Cui Z L, Yue S C, Zhang F S, et al Alternative cropping systems for sustainable water and nitrogen use in the North China Plain. Agriculture Ecosystems and Environment, 2012; 146: 93-102.

[34] Gupta N, Gupta A K, Gaur V S. Relationship of nitrogen use efficiency with the activities of enzymes involved in nitrogen uptake and assimilation of finger millet genotypes grown under different nitrogen inputs. Scientific World Journal, 2012; 10: 625731.

[35] Chen K., Kumudini S, Tollenaar M, Vyn T. Plant biomass and nitrogen partitioning changes between silking and maturity in newer versus older maize cultivar. Field Crops Research, 2015; 183: 315-328.

[36] Ciampitti I A, Murrell S T, Camberato J J, Tuinstra M, Xia Y, Friedemann $\mathrm{P}$, et al. Physiological dynamics of maize nitrogen uptake and partitioning in response to plant density and nitrogen stress factors: II. Reproductive phase. Crop Science, 2013; 53: 2588-2602.

[37] Mon J, Bronson K F, Hunsaker D J, Thorp K R, White J W, French A N Interactive effects of nitrogen fertilization and irrigation on grain yield canopy temperature, and nitrogen use efficiency in overhead sprinkler-irrigated durum wheat. Field Crops Research, 2016; 1: 54-65.

[38] Ning P, Li S, Yu P, Zhang Y, Li C J. Post-silking accumulation and partitioning of dry matter, nitrogen, phosphorus and potassium in maize cultivars differing in leaf longevity. Field Crops Research, 2013; 144: 19-27.

[39] Valentinuz O R, Matthijs T. Vertical profile of leaf senescence during the grain-filling period in older and newer maize hybrids. Crop Science, 2004; 44, 827-834 
[40] Mu X H, Chen Q W, Chen F J, Yuan L X, Mi G H. Dynamic remobilization of leaf nitrogen components in relation to photosynthetic rate during grain filling in maize. Plant Physiology and biochemistry, 2018; 18: 27-34.

[41] Poorter H, Evans J R. Photosynthetic nitrogen use efficiency of species that differ inherently in specific leaf area. Oecologia, 1998; 116: 26-37.

[42] Sinclair T R, Horie T. Leaf nitrogen, photosynthesis, and crop radiation use efficiency: A review. Crop Science, 1989; 29: 90-98.

[43] Hikosaka K. Interspecific difference in the photosynthesis nitrogen relationship: Patterns, physiological causes, and ecological importance. Journal of Plant Research, 2014; 117: 481-494.

[44] Pan W L, Camberato J J, Moll R H, Kamprath E J, Jackson W A. Altering source-sink relationships in prolific maize cultivars: Consequences for nitogen uptake and remobilization. Crop Science, 1995 35: 836-845.

[45] Su W, Kamran M, Xie J, Meng X, Han Q, Liu T, Han J. Shoot and root traits of summer maize hybrid varieties with higher grain yields and higher nitrogen use efficiency at low nitrogen application rates. Peer J. 2019; 7: e7294.

[46] Bernard S V M, Habash D Z. The importance of cytosolic glutamine synthetase in nitrogen assimilation and recycling. New Physiology, 2009; 182: 608-620.

[47] Wang X C, Wang X H, Xiong S P, Ma X M, Ding S J, Wu K Y, et al Differences in nitrogen efficiency and nitrogen metabolism of wheat varieties under different nitrogen levels. Science Agricultural Sinience, 2015; 48: 2569-2579.

[48] Ye X S, Hong J, Shi L, Xu F S. Adaptability mechanism of nitrogen-efficient germplasm of natural variation to low nitrogen stress in Brassica napu. Journal of Plant Nutrition, 2010; 33: 2028-2040.

[49] Zhu X G, de Sturler E, Long S P. Optimizing the distribution of resources between enzymes of carbon metabolism can dramatically increase photosynthetic rate: a numerical simulation using an evolutionary algorithm. Plant Physiology, 2007; 145: 513-526.

[50] Mu X H, Chen Q W, Chen F J, Yuan L X, Mi G H. Within-leaf nitrogen allocation in adaptation to low nitrogen supply in maize during grain-filling stage. Front Plant Science, 2016; 7: 699.

[51] Zhang M W, Dong Y M, Ma G, Wang C Y, Xie X D, Kang G Z Responses of glutamine synthetase activity and gene expression to nitrogen levels in winter wheat cultivars with different grain protein content. Journal of Cereal Science, 2017; 74: 187-193. 